\title{
O FORTALECIMENTO DOS BANCOS COMUNITÁRIOS A PARTIR DA ORGANIZAÇÃO EM REDE: O CASO DA REDE BAIANA DE BCDS
}

Magno Willams De Macêdo Farias ${ }^{1}$

Adrianne Garcia Corrêa Silva ${ }^{2}$

Maria Elena Leon Olave ${ }^{2}$

${ }^{1}$ Programa de Mestrado Acadêmico em Administração / Pró-Reitoria de Pós-Graduação e Pesquisa / Universidade Federal de Sergipe

${ }^{2}$ Universidade Federal de Sergipe 


\section{O FORTALECIMENTO DOS BANCOS COMUNITÁRIOS A PARTIR DA ORGANIZAÇÃO EM REDE: O CASO DA REDE BAIANA DE BCDS}

Resumo: As redes de economia solidária articulam os setores do Estado e da Sociedade Civil atuando na elaboração teórica e apoio a empreendimentos solidários. Este estudo teve como objetivo analisar como a Rede Baiana de BCDs tem contribuído para o fortalecimento dos bancos comunitários da Bahia. A metodologia aplicada neste estudo propõe uma abordagem qualitativa, de natureza descritiva e exploratória. Utilizou-se o estudo de caso como estratégia de pesquisa. Concluiu-se que a Rede Baiana tem colaborado de forma significativa para superar os desafios enfrentados pelos bancos, permitindo que seus participantes possam se articular, compartilhar informações, trocar experiências, receber auxilio técnico e acessar recursos. Suas ações, de modo geral, têm fortalecido os bancos existentes, dando-lhes maior visibilidade e ampliando sua oferta de serviços, além de atuar no apoia a expansão dessas experiências com a constituição de novos bancos, fortalecendo o movimento de economia solidária, como também a própria rede.

Palavras-chave: Redes. Redes de Economia Solidária. Bancos Comunitários. 


\section{Introdução}

O sistema econômico tradicional vem dando sinal de falência e seu modelo de desenvolvimento baseado na acumulação da riqueza por parte de uma minoria e exclusão do sistema financeiro da grande parcela da população mundial vem contribuindo para aumentar a crise do trabalho. Como resposta a este modelo, alternativas de desenvolvimento veem sendo pensadas e implementadas, alternativas estas que buscam um novo modelo de desenvolvimento e novas formas de geração de trabalho e renda (CASSANDRE et al., 2013).

Uma das alternativas que vem despontando em diversas formas de organizações, inclusive sociais, são as redes de economia solidária, que segundo Mance (1999) são organizações sociais de caráter econômico, político e cultural, que, sob aspectos econômicos, articulam grupos de consumidores, produtores e prestadores de serviços em laços de realimentação. Tais redes articulam os setores do Estado e da Sociedade Civil atuando na elaboração teórica e apoio a empreendimentos solidários (HIGA, 2005). Além disso, essas podem ser vistas como uma estratégia para integrar grupos de consumo, cooperativas, sindicatos, movimentos populares, grupos de produção, e outros, de maneira tal que todos possam se fortalecer e avançar juntos, construindo uma nova sociedade, sendo também uma alternativa ao combate da economia informal (HART, 1973; GODFREY, 2011).

No Brasil, a Secretaria Nacional de Economia Solidária (SENAES), criada em 2003, teve papel importante no fomento das redes de economia solidária, com o proposito de apoiar a geração de trabalho e renda nas camadas mais pobres da população, como também no fomento a empreendimentos de finanças solidarias como cooperativas de créditos solidárias, fundos rotativos solidários e bancos comunitários, através de editais públicos, com vistas a inclusão financeira dessa população ( RIGO; FRANÇA FILHO; LEAL, 2015). Segundo dados do IPEA/SIPS (2011), 39,5\% da população brasileira não possui conta bancária. Na região Nordeste, esse quadro se agrava alcançando $52,6 \%$. Os bancos comunitários de desenvolvimento se colocam como alternativa no combate a essa exclusão, proporcionando às comunidades um desenvolvimento econômico antes deficiente. O primeiro banco comunitário surgiu em Fortaleza em 1998 e recebeu o nome de Banco Palmas. Em 2016 esses bancos somaram-se 117 iniciativas espalhadas por diversos municípios de diferentes estados brasileiros. Essas instituições vêm se articulando em rede desde 2004, quando foi criada a Rede Brasileira de Bancos Comunitários. Além da Rede Brasileira, também surgiram ao longo dos últimos anos redes estaduais e regionais de bancos comunitários, como a Rede Nordeste de BCDs, a Rede Cearense, a Rede Capixaba e a Rede Baiana. A Rede Baiana foi criada em 2010 e conta hoje com oito bancos comunitários.

Nesse contexto, esse estudo tem como objetivo analisar como a Rede Baiana de BCDs contribui para o fortalecimento dos bancos comunitários da Bahia. Foram elencados objetivos específicos norteadores para alcançar o objetivo proposto: (1) entender a forma de organização e gestão da Rede Baiana de BCDs; (2) mapear as principais atividades da rede desde a sua criação; (3) identificar os principais benefícios alcançados pela rede de forma coletiva e (4) verificar os benefícios alcançados individualmente para os 05 BCDs entrevistados.
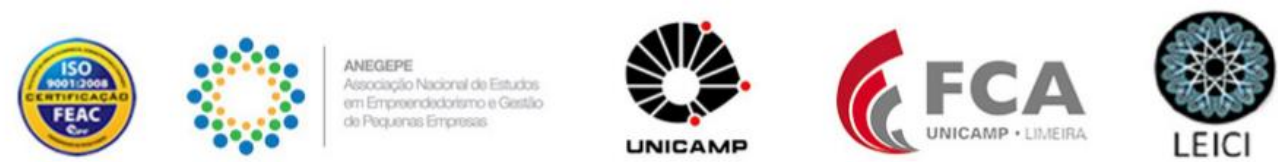
O artigo apresenta-se estruturado da seguinte maneira: revisão da literatura dividida em dois tópicos: Redes de Economia Solidária e Bancos Comunitários de Desenvolvimento, seguindo para o detalhamento dos procedimentos metodológicos. Em seguida, será realizada caracterização das empresas estudadas, junto a análise dos dados coletados, finalizando com as conclusões baseadas nos dados analisados e sugestões para pesquisas futuras.

\section{Referencial Teórico}

\subsection{Redes de Economia Solidaria}

Com o fortalecimento do capitalismo gerencial no século XIX, as organizações empresariais passaram a ser caracterizadas pela burocratização e pela alta competição. Porém, o cenário econômico do mercado sofre transformações no final do século XX, estabelecendo modificações na maneira como os negócios eram conduzidos (VERSCHOORE, 2006). As pressões exercidas pelo mercado, que se tornou cada vez mais competitivo, fizeram surgir as organizações coletivas de livre iniciativa ou fomentadas por órgãos agenciadores de desenvolvimento que somadas as pressões de necessidades sociais em determinadas regiões do país, a exemplo da necessidade de desenvolvimento econômico de comunidades, promoveram a confecção de uma teia que entrelaça pessoas, organizações e objetivos (GUARDA, 2010). As competências exigidas pelos consumidores do século XXI obrigaram as empresas e organizações a desenvolver um modelo de cooperação entre si, a fim de que fossem capazes de suprir as lacunas existentes em seus negócios (CASTELLS, 1999; VERSCHOORE, 2006).

Para Guarda (2010) esses fatores remetem essas organizações a buscarem sua complementariedade, articulando forças em redes. Segundo Macieirinha (2009), uma rede é composta por atores que visam um objetivo comum, com prazo indeterminado, que participam diretamente das decisões, beneficiando-se dos ganhos e benefícios igualitariamente, tudo isso sem que a sua individualidade seja extinta. A noção de rede coloca ênfase nas relações entre diversidades que se integram, nos fluxos de elementos que circulam nessas relações, nos laços que potencializam a sinergia coletiva, no movimento de auto-organização em que cada elemento auxilia no desenvolvimento do outro, na potencialidade de transformação de cada parte pela sua relação com as demais e na transformação do conjunto pelos fluxos que circulam através de toda rede (MANCE, 2002).

Atualmente, o modelo de redes é bastante difundido entre diversas esferas da sociedade, inclusive em organizações sociais. Dowbor (2008, p.98) afirma que "as atividades hoje se tornaram muito mais amplas, complexas e interativas, fazendo com que as economias de colaboração, materializadas no capital social, sejam cada vez mais importantes". Guarda (2010) sugere que a rede de cooperação tomou seu espaço nas diversas formas de organização, sejam elas empresariais com finalidades econômicas, sociais, sem e com fins lucrativos, e principalmente redes de cooperação solidaria com objetivo de construir outras lógicas de produção, consumo e articulação política.

Essas redes de economia solidária, segundo Mance (2003), podem ser vistas como uma estratégia para integrar grupos de consumo, cooperativas, sindicatos, movimentos populares, grupos de produção, e outros, de maneira tal que todos possam se fortalecer e avançar juntos, construindo uma nova sociedade. Para França Filho e Cunha
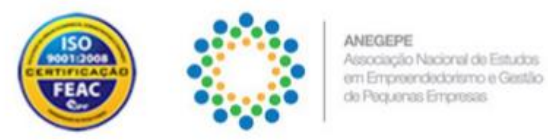

Realizadores:
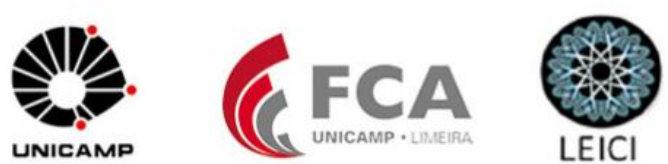
(2009), as redes locais de economia solidária desenvolvem um papel fundamental na restruturação da economia local de uma comunidade. Essas redes locais são compostas pela associação de vários empreendimentos coletivos que visam a construção de um circuito próprio de relações econômicas, troca de experiências, informações sobre atividades e outras organizações, rede de contatos, além da redução de custos fixos em determinadas situações (FRANÇA FILHO; CUNHA, 2009; BRAZ; CARDOSO, 2013). Para que a cooperação em redes de empreendimentos solidários seja eficaz, é necessário que haja confiança e valorização mútua entre os indivíduos, pressupondo a existência de relacionamentos interpessoais baseados em laços (GRANOVETTER, 1973; BRAZ; CARDOSO, 2013).

As redes de economia solidária também se mostram como uma alternativa ao combate da economia informal, que é consequência de problemas sociais e que tem se solidificado enquanto movimento econômico (HART, 1973; GODFREY, 2011). Gaiger (2009), em seu estudo sobre associação econômica dos pobres como via de combate às desigualdades, sugere que o termo "economia solidária" refere-se a práticas econômicas de pessoas associadas livremente, cujas características em comum são: (1) algum grau de socialização dos meios de produção; (2) dispositivos de cooperação no trabalho; (3) elementos de gestão democrática; (4) envolvimentos em ações mais amplas, a partir do entorno dos empreendimentos (LAVILLE; GAIGER, 2009). Essas práticas também vêm sendo estudadas em outros países da América Latina e do mundo (CORAGGIO, 2012).

Mance (2002) aponta critérios básicos de participação nas redes de Economia Solidária, que não haja qualquer tipo de exploração, que o empreendimento seja ou se transforme em ecologicamente sustentável, compartilhe os excedentes para alavancar o crescimento da rede e que exista a autogestão, cooperação e colaboração. Essas redes podem abranger uma série de empreendimentos e iniciativas em distintos campos na sua base territorial, como: de consumo ético, finanças solidárias, tecnologias livres, comércio justo, produção autogestionária e serviços locais, entre outros, além da articulação dos atores externos governamentais e não-governamentais. Neste sentido, supõe haver nessas redes, "articulações entre iniciativas de distintas naturezas - socioeconômicas, sociopolíticas, socioculturais e socioambientais. Além disso, ela admite diferentes níveis de articulação com a economia local preexistente" (FRANÇA FILHO; CUNHA, 2009b).

Os bancos comunitários, no campo das finanças solidárias, vêm se articulando em rede desde 2004, quando foi criada a Rede Brasileira de Bancos Comunitários. Segundo Rigo e Cansado (2015), a Rede Brasileira de BCDs atualmente é o principal espaço público criado e utilizado pelos BCDs no tocante ao processo de institucionalização e sustentabilidade das iniciativas por todo o país. Ainda segundo Rigo e Cansado (2015) é nesse espaço que vem sendo discutida a importância da criação de um marco legal regulatório para os BCDs e o uso de moedas sociais. Além das formas de apoio e financiamento público.

\subsection{Bancos Comunitários de Desenvolvimento (BCDs)}

O primeiro banco comunitário no Brasil surgiu em 1998 na periferia de Fortaleza no Ceará. Desde seu surgimento o Banco Palmas tem incentivado o desenvolvimento de novos bancos comunitários. Os bancos comunitários de desenvolvimento (BCDs)
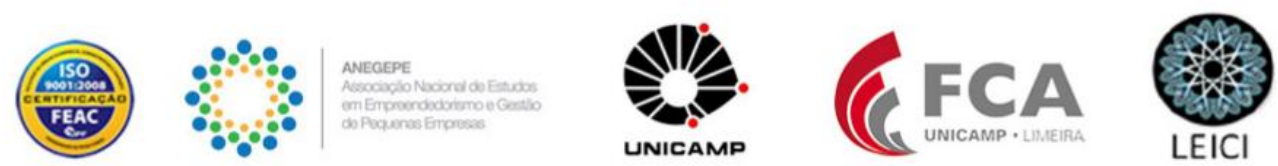
podem ser definidos como uma prática de finanças solidárias de apoio a economias populares de territórios com baixo índice de desenvolvimento humano (FRANÇA FILHO e SANTANA, 2013; FREIRE, 2013; FRANÇA FILHO, 2013). Para Melo Neto e Magalhães (2007) os BCDs são serviços financeiros solidários em rede, de natureza associativa e comunitária, voltados para geração de trabalho e renda, tendo por base os princípios da Economia Solidária.

Segundo os dados do último mapeamento do Sistema Nacional de Economia Solidária (SIES) realizado em 2012 existem hoje 19708 empreendimentos de economia solidária, dos quais $40,8 \%$ estão localizados na região Nordeste. Dentre o total de empreendimentos $1,7 \%$ estão classificados como de poupança, crédito ou finanças solidárias, entre estes 117 são Bancos Comunitários de Desenvolvimento. Baseando-se numa lógica de economia solidária, "os BCDs ratificam a construção de uma outra economia, cuja a vocação maior é de produção e preservação da vida num determinado contexto territorial, conforme o significado original da economia" (FRANÇA FILHO, 2010, p.4). Melo Neto e Magalhães (2007) argumentam que a própria comunidade é quem decide criar o banco, e dele se torna gestora e proprietária. Suas linhas de crédito estimulam a criação de uma rede, uma vez que apoiam a comercialização local, atuando em territórios caracterizados por exclusão, vulnerabilidade e desigualdades.

Ao argumentar sobre a finalidade de um BCD, Singer (2013) aponta que seu objetivo não é maximizar seu lucro, como fazem os bancos privados, mas fomentar o desenvolvimento de comunidades que o criou e o utiliza.

Estas iniciativas ao confirmar seu potencial em promover uma efetiva inclusão financeira, principalmente ao atingir a população de mais baixa renda, podem ser vistas, segundo Rigo (2014), como instituições criadas para ocupar um espaço deixado por um movimento de afastamento do mercado em relação à sociedade; ou ainda, de uma parcela da sociedade que a maioria das instituições financeiras de mercado não se interessa por integrar.

Segundo França Filho (2010), a ousadia de um BCD é de tentar restaurar laços e vínculos sociais seriamente degradados pelas condições de vidas mais geral das pessoas nos bairros populares, por meio de um novo tipo de relação com o dinheiro e organização da vida econômica local. Para tal propósito essas iniciativas contam com uma lógica de funcionamento e gestão fundada na participação democrática e empoderamento das pessoas no seu processo de gestão (FRANÇA FILHO, 2010). Outro ponto a ser destacado na dinâmica funcionamento de um BCD está relacionado com a sua sustentabilidade. Segundo França Filho e Santana (2013) o modo como os BCDs se mantém repousa sobre uma articulação de diferentes lógicas de organização econômica, o que torna incompatível sua sustentabilidade sob a égide do conceito convencional de viabilidade econômica, o que o torna totalmente dependente de recursos do seu ambiente externo. Segundo Melo Neto e Magalhães (2007, p. 9) "sua sustentabilidade se dá por meio da capitação de recursos públicos e da constituição de um fundo solidário investimento de comunitário".

A dificuldade em consolidar-se como empreendimento autossustentável tem levado a boa parte destas iniciativas a reduzirem sua capacidade de atuação ou até mesmo paralisar temporariamente suas atividades. Rigo (2014) ao investigar a situação atual dos BCDs no Brasil, identificou que apenas 59,6\% estavam em pleno funcionamento.
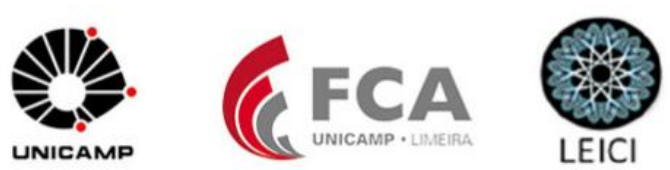
Entre os 40,4\% restantes, $29,8 \%$ estavam funcionado parcialmente, ou seja, o BCD havia diminuído suas atividades e o atendimento às solicitações de crédito, mas continuava aberto ao público e gerenciando os recursos, a circulação da moeda social e outras atividades relativas aos projetos sociais, e $10,6 \%$ estavam temporariamente sem atividade.

Ainda segundo Rigo (2014) no caso dos BCDs da região Nordeste, quase a metade dos BCDs investigados não tem funcionado plenamente. Os principais motivos identificados pela autora para essa realidade foram a falta de fundo de crédito, dificuldades relativas à circulação e ao empréstimo com a moeda social e dificuldades para pagamento das despesas. $\mathrm{Na}$ Bahia atualmente existem 8 bancos comunitários, mas destes, apenas 4 estão em pleno funcionamento, 1 encontra-se funcionando parcialmente e 3 estão com suas atividades temporariamente paralisadas.

Diante das dificuldades enfrentadas por estes BCDs existem alguns elementos que apontam para sua reorganização de forma que estes se apoiem mutuamente. Essa reorganização ocorre, principalmente, pelos processos de fortalecimento por meio da rede estadual de bancos na Bahia.

\section{Metodologia}

A metodologia aplicada neste estudo propõe uma abordagem qualitativa, de natureza descritiva e exploratória. Utilizou-se o estudo de caso como estratégia de pesquisa, que segundo Yin (2015), é adequado para análises que não necessitam controle sobre eventos comportamentais, mas focalizam acontecimentos contemporâneos. Dentro desse conceito, optou-se pelo estudo de caso único integrado, que se apresenta como uma escolha quando, em um caso único, a atenção também é dirigida a subunidades de análise (YIN, 2015). Como fundamento para a utilização dessa estratégia de pesquisa foram observados dois aspectos:

a) Escassez de informação sobre o tema;

b) Complementaridade de informações quando analisadas as subunidades da Rede observada.

O critério de escolha do caso foi acessibilidade dos pesquisadores à rede. Como unidade de análise desse estudo, foi selecionada a Rede Baiana de Bancos Comunitários de Desenvolvimento, formada atualmente por 8 (oito) bancos comunitários de desenvolvimento e pela Incubadora Tecnológica de Economia Solidária e Gestão do Desenvolvimento Territorial (ITES/UFBA), dos quais 6 (seis) serão as subunidades de análise do estudo.

Segundo Eisenhardt (1989), os estudos de caso combinam métodos de coleta de dados, tais como arquivos, entrevistas, questionários e observações. Dessa forma, quanto à coleta de dados, o estudo baseou-se em entrevistas individuais semiestruturadas, realizada com os agentes locais de desenvolvimento dos bancos escolhidos. As agentes entrevistadas foram identificadas por letras, com objetivo de preservar a identidade das mesmas. Segundo Laville e Dionne (1999: p.188) a entrevista semiestruturada permite a realização de uma série de perguntas abertas, feitas verbalmente em uma ordem prevista, mas na qual o entrevistador pode acrescentar perguntas de esclarecimentos. Ela ainda permite que o entrevistado formule uma resposta pessoal, obtendo uma ideia melhor do que esse realmente pensa e se certifica na mesma ocasião de sua competência. Sua
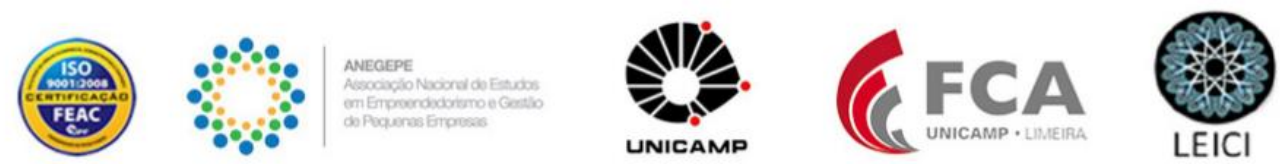
flexibilidade possibilita um contato mais íntimo entre entrevistador e entrevistado, favorecendo assim a exploração em profundidade de seus saberes, bem como de suas representações, crenças e valores (LAVILLE; DIONNE, 1999, p. 189). Foi realizado ainda pesquisa documental de relatórios da Rede Baiana de BCD, que segundo Godoy (1995) constitui uma rica fonte de dados.

Para a escolha dos entrevistados levou-se em consideração o tempo de pertencimento do banco na Rede e sua ativa participação. Assim foram entrevistados os representantes dos BCDs que fazem parte da rede a mais de um ano e que seu representante tenha participado de no mínimo 4 encontros da rede nos últimos dois anos. Esses critérios justificam-se, primeiro devido ao fato de que um banco que esteja a menos de uma ano na rede não tenha se apropriado de todos os processos, não sendo assim possível identificar os benefícios da participação em rede, tanto coletivamente, como também individualmente. Em segundo lugar o banco que não tenha participado ao menos de quatro reuniões nos últimos dois anos não teria como identificar quais tem sido os benefícios alcançados pela rede baiana nos últimos anos, como também não saberá informar qual estágio atual da mesma. Por esses critérios deixaram de participar desta pesquisa o Banco Amigos do Sertão, que ingressou na rede no último dia 18, após sua inauguração, e o Banco Comunitário Santa Luzia que, embora seja um dos fundadores da rede, não vem participando da mesma desde 2014, quando teve suas atividades parcialmente paralisadas.

No tocante às categorias de análise, foram definidas, com base nos objetivos, as seguintes:

Quadro 1: Categorias e elementos de análise

\begin{tabular}{|l|l|}
\hline Categorias de análise & Elementos de análise \\
\hline Organização da rede local de economia solidária & Descrever estrutura da rede; mapear atividades. \\
\hline Benefícios da rede & $\begin{array}{l}\text { Benefícios alcançados pela rede; benefícios } \\
\text { alcançados individualmente pelos bancos por } \\
\text { meio da rede por meio das redes. }\end{array}$ \\
\hline Percepções sobre a Rede Baiana & $\begin{array}{l}\text { Situação atual da rede (fortalecimento ou } \\
\text { fragilidade); desafios e dificuldades para sua } \\
\text { manutenção. }\end{array}$ \\
\hline
\end{tabular}

Fonte: Elaborado pelos autores.

Após a coleta dos dados, as entrevistas gravadas foram transcritas e utilizou-se a técnica da análise de conteúdo para a análise das informações captadas. Para o tratamento das informações obtidas utilizou-se a técnica de análise de conteúdo. De acordo com Laville e Dionne (1999: p.205) a análise de conteúdo permite abordar uma grande diversidade de objetos de investigação como: atitudes, valores, representações, mentalidades, ideologias, entre outros.

\section{Descrição e análise dos casos}

Nessa seção, foi feita a descrição da Rede Baiana de Bancos Comunitários de Desenvolvimento, suas atividades e seus princípios. Em seguida, a análise do caso por meio das entrevistas, norteadas pelas categorias de análise dispostas no Quadro 01.

\subsection{Rede Baiana de Bancos Comunitários de Desenvolvimento}

A Rede Baiana de Bancos Comunitários foi fundada em 2010 pelos bancos comunitários do Estado da Bahia. Na ocasião fizeram parte da criação da rede os quatro 
banco existentes no período, banco Ilhamar, banco Casa do Sol, banco Guine, Banco Santa Luzia, além da ITES. Hoje, a rede conta com a entidade de fomento ITES e com oito bancos comunitários. O objetivo da rede é fortalecer as ações dos BCDs promovendo meios de apoio e suporte técnico, e através de intercâmbio de experiências, parcerias e da participação das comunidades na definição de estratégias próprias, promovendo os princípios da economia e das finanças solidárias para desenvolver as comunidades locais, propondo ações e políticas públicas de BCDs. Além disso, promove discussões envolvendo questões relativas à gestão e operação de BCDs, orientações e estratégias para o desenvolvimento comunitário, superação das desigualdades e geração de emprego e renda.

\subsection{Análises dos dados}

De acordo com os dados gerados a partir das entrevistas e coleta de documentos, foi feita a análise do caso da Rede Baiana de BCDs.

Em relação a gestão da rede, foram obtidos documentos que mostram a sua estrutura de coordenação, tendo cada membro um representante. Todos os membros da rede confirmaram que a sua gestão e por consequência as decisão são tomadas de forma conjunta e todos têm poder de voto e mesmo peso. Essa é uma das características de redes de cooperação encontrada na literatura, que segundo Macieirinha (2009), é formada por atores com objetivos em comum, com prazo indeterminado, que participam diretamente das decisões, beneficiando-se dos ganhos igualitariamente. Apesar dessa afirmação, percebeu-se que existe uma certa condução da gestão por parte da ITES, a incubadora vinculada a Universidade Federal da Bahia; esse fato não é reflexo de uma imposição por parte da incubadora, mas da falta de um sentimento de empoderamento por parte dos bancos, fator fundamental em iniciativas sociais, como afirma França Filho (2010).

A maior parte bancos, mas não todos, ainda enxergam a ITES como a coordenadora do processo, talvez pelo fato de que ela tenha sido a fundadora da rede e detenha a "teoria", como citado pelo banco Quilombola do Iguapé. A própria incubadora, apesar de saber que tem tanto poder quanto o restante dos membros, entende que, de certa forma, é a condutora do processo, conforme fala de sua representante:

\footnotetext{
“Às vezes, a participação dentro dos encontros fica restrita a poucas pessoas. Normalmente quem puxa as reuniões, quem dá as boas-vindas, quem propõe pauta é sempre a ITES. Até hoje foram poucos os momentos quem eles conduziram um evento (...) Eu sinto que sempre alguma pessoa da ITES centraliza alguma responsabilidade ou acaba solicitando alguma demanda para o resto do grupo (...) se você não puxar algo, por eles mesmos não acontece (...). A gestão se propõe a ser horizontal dentro da rede, onde todos têm o mesmo poder de voto, tem total autonomia pra decisão, mas acaba que os representantes da incubadora acabam puxando o processo (entrevistada A)".
}

A experiência da ITES ao logo dos anos a frente desses processos em que se observou que quando se afastava do processo, a rede ficava parada, faz com que ela tenha um cuidado maior nesse processo; em outros casos, ainda, a incubadora precisou se responsabilizar por algumas ações, pois os membros se eximiram da responsabilidade. Apesar de haver uma gestão democrática, que segundo Gaiger (2009), constitui-se como 
um dos principais elementos da rede, os atores não estão em equilíbrio quanto a percepção da sua responsabilidade enquanto gestor da rede.

No tocante à importância da rede, é unânime que a rede tem auxiliado no fortalecimento dos bancos, proporcionando interação, comunicação, propagação de informações, capacitação, intercâmbios com outras instituições e auxilio técnico. A rede já fez a reabertura de bancos que estavam fechados e a capacitação de agentes para atuar em sua gestão.

\begin{abstract}
"Desse período, eu já vi a rede inaugurar alguns bancos, dois ou foram três, se não me engano (...) o pessoal está fazendo capacitação com as agentes, então eu acho que a rede tem feito seu papel com frequência... de capacitação, de incentivar a rede a correr atrás de recursos para os bancos, então tem incentivado muito, principalmente na parte financeira e de capacitar pessoal" (Entrevistada B).
\end{abstract}

É interessante notar um contraste no que diz respeito à percepção da importância da rede por parte dos bancos, mas ainda assim identificar a certa falta de responsabilidade e compromisso com a rede. Os bancos entendem o benefício que a rede tem atraído, principalmente no tocante a oportunidades de capacitação e intercâmbios e da visibilidade que a rede consegue proporcionar, mas ainda assim têm falhado no compromisso de estarem juntos em reuniões e eventos, discutindo o futuro da rede. Esse comportamento enfraquece os laços entre os atores, que passam a não sentir confiança mútua (GRANOVETTER, 1973; BRAZ; CARDOSO, 2013).

\begin{abstract}
"Eu, no geral, estou achando que as pessoas estão mais desinteressadas, porque eu vejo as meninas tentando fazer uma reunião e não deu certo isso enfraquece a rede(...) também tem o problema do deslocamento, a maioria são mulheres e fica difícil ficar três dias fora. Eu mesmo, tenho marido e filhos, para ir para uma reunião tenho que sair um dia antes e voltar um dia depois e nem sempre dá 'pra' ir" (Entrevistada C).
\end{abstract}

Quanto aos benefícios proporcionados pela rede, eles vão desde benefícios individuais, tanto pessoais quanto profissional, para os atores que fazem parte da rede e benefícios para os bancos, para a rede e para o movimento de economia solidária. Como benéficos pessoais foram apontados a participação em intercâmbios, encontros, reuniões, geração de renda e o recebimento de bolsas auxilio, que estimulam, motivam e aumenta a autoestima. Em relação aos benefícios profissionais foram mencionados as capacitações, trocas de experiências, ajuda mutua que melhoram a capacidade de atuação no dia a dia do banco. Ambas auxiliam na melhoria da gestão do BCD, geram conhecimento, profissionalizam e abrem portas. Esses resultados corroboram com as colocações de Mance (2010) que afirma que as iniciativas que nascem da auto-organização vêm auferindo grandes benéficos aos trabalhadores, propiciando motivação e promovendo a confiança mútua no outro, restaurando as condições objetivas e subjetivas para que as pessoas cumpram seu papel social.

Os benéficos para o movimento de economia solidária se confundem com o os benéficos da própria rede e do próprio banco, como o aumento do número de iniciativas, a recuperação e fortalecimento dos BCD fragilizados e maior visibilidade. Além destes benefícios, os bancos melhoraram sua gestão interna, aumentaram suas parcerias, estão mais articulados politicamente, capitaram mais recursos e aumentaram a oferta de produtos e serviços, beneficiando também as comunidades aos quais pertencem. 
"O benefício não é diretamente 'pro' banco, mas pro movimento de finanças e economia solidária (...) a rede traz um benefícios que articulação política, o benefício de pertencimento a um grupo. Hoje as pessoas estão mais engajadas, interessadas pela Rede Baiana, quer que ela se perpetue (...) a gente fez uma oficina de excel, é benefício 'pros' bancos, né? (...) os bancos da Rede Baiana puderam participar do último curso de correspondente bancário (...) e tem os benefícios também indiretos, capacitação, participação, intercâmbios (...) Agrega para o banco conhecer outras realidades"(Entrevistada A).

Em relação a atual situação da rede no tocante ao seu fortalecimento ou enfraquecimento não há um consenso entre os membros da rede. Dos sete agentes entrevistados, quatro acreditam que a rede ainda está fortalecida, três acreditam que ela está enfraquecida. Os motivos que embasam a opinião de que a rede se encontra enfraquecida são: falta de responsabilidade dos membros com atividades da rede, falta de compromisso e falta de interesse.

"Eu, no geral, estou achando que as pessoas estão mais desinteressadas, porque eu vejo as meninas tentando fazer uma reunião e não deu certo isso enfraquece a rede(...) também tem o problema do deslocamento, a maioria são mulheres e fica difícil ficar três dias fora. Eu mesmo, tenho marido e filhos, para ir para uma reunião tenho que sair um dia antes e voltar um dia depois e nem sempre dá 'pra' ir" (Entrevistada D).

Os entrevistados acreditam que esse comportamento tem feito com que a rede produza bem mais aquém do que poderia produzir, caso houvesse uma participação mais sólida de todos os membros. Os adeptos a esse pensamento temem pela dissolução da rede por falta de recursos, uma vez que alguns membros não têm se empenhado em auxiliar nessa captação. A dissolução da rede, segundo esses membros, acarretaria, muito provavelmente, no encerramento dos bancos que já estão mais fragilizados.

"A rede tem que continuar, a rede baiana é muito importante para os bancos comunitários, mas agora para rede funcionar todos os bancos tem que participar. Se as pessoas não voltarem a se envolver na rede e ela acabar vai ser horrível, vai prejudicar os bancos. Com a rede tem como se reunir, fazer projetos, conversar com outras pessoas de outros bancos e sem a rede isso tudo acaba" (Entrevistada E).

Por outro lado, a maioria dos membros da rede, apesar de enxergar e apontar exatamente o mesmo problema, não acredita que esse motivo por si só é suficiente para afirmar que a rede está enfraquecida e que esse seria apenas um dos fatores. Ainda assim, acreditam que a Rede Baiana conseguiu construir um nome sólido e de credibilidade no estado da Bahia e no campo da economia solidária.

Eu acho que ela está mais fortalecida, ela tem dado oportunidades que sem ela não existiriam. A rede existe para que esses bancos possam se encontrar, e é isso que faz a rede, então se a gente não tivesse a oportunidade de estar se encontrando, de estar trocando ideias, levando experiências uns para os outros, talvez alguns bancos não existissem mais" (Entrevistada F).

As dificuldades e desafios apontados pelos membros da rede versaram sobre questões políticas e econômicas, desmobilização e fragilidade das entidades gestoras dos BCDs. Em relação a preocupação com o cenário políticos e econômico há consenso na rede que a atual conjuntura tem prejudicado a capacidade de articulação da rede devido à redução de recursos provenientes de editais públicos, principal fonte de financiamento das atividades da rede. Esse cenário é preocupante, visto que segundo Melo 
Neto e Magalhães (2007) a principal fonte de sustentabilidade dessas iniciativas advém do setor público.

Não há na rede um consenso em relação aos motivos que tem gerado o processo de desmobilização entre os atores para participar das atividades da rede, principalmente as reuniões. Foram apontados ao menos quatro motivos diferentes para a redução da participação nas atividades. Alguns bancos apontam que isso é fruto da falta de compromisso e desinteresse de alguns participantes. Entretanto outros atores apontaram que os principais motivos para a redução da participação estão relacionados com a falta de estrutura dos bancos que estão mais fragilizados, como no caso dos bancos que possuem apenas uma agente de crédito e não podem paralisar suas atividades para participar das reuniões. Um terceiro motivo está relacionado às agendas dos próprios bancos e as agendas das entidades gestora que tem coincidido com as reuniões dos bancos.

"Cada BCDS tem as vezes uma agenda e as vezes as agentes tem uma agenda em cima de outra agenda. Mas essas questões quando nós encontramos vamos discutir em rede, mas que elas existem, elas existem, não tem como negar e tem que ser resolvida" (Entrevistada G).

E o quarto e último motivo apontado, esse parecer ser um mais crítico, está relacionado à distância entre os bancos. Para participar de uma reunião de apenas um dia, algumas agentes precisam se ausentar por até três dias de suas atividades e de suas famílias, o que é bastante complicado principalmente pelo fato de a maioria ser mães. 
Quadro 2: Resumo dos resultados de todos as organizações.

\begin{tabular}{|c|c|c|c|c|c|c|c|}
\hline \multirow{2}{*}{$\begin{array}{c}\text { Categorias de } \\
\text { análise }\end{array}$} & \multirow[t]{2}{*}{ Elementos de análise } & \multicolumn{6}{|c|}{ Resultados } \\
\hline & & ITES/UFBA & Banco Ilhamar & $\begin{array}{c}\text { Banco Casa do } \\
\text { Sol }\end{array}$ & $\begin{array}{c}\text { Banco Quilombola } \\
\text { do Iguape }\end{array}$ & $\begin{array}{l}\text { Banco Abrantes } \\
\text { Solidário }\end{array}$ & Banco BAMEX \\
\hline \multirow[t]{5}{*}{$\begin{array}{l}\text { Organização da } \\
\text { rede de economia } \\
\text { solidária }\end{array}$} & \multirow{3}{*}{$\begin{array}{c}\text { Percepção sobre a } \\
\text { forma de } \\
\text { organização da Rede } \\
\text { Baiana }\end{array}$} & $\begin{array}{l}\text { Todos os membros } \\
\text { possuem mesmo } \\
\text { poder de voto; }\end{array}$ & \multirow[t]{3}{*}{$\begin{array}{l}\text { Não existe uma } \\
\text { coordenação. }\end{array}$} & $\begin{array}{l}\text { Misto de teoria e } \\
\text { prática; }\end{array}$ & $\begin{array}{l}\text { Misto de teoria e } \\
\text { prática; }\end{array}$ & $\begin{array}{l}\text { Coordenada pela } \\
\text { ITES; }\end{array}$ & \multirow[t]{3}{*}{$\begin{array}{l}\text { Gerida por } \\
\text { representante de todos } \\
\text { os BCDs da rede. }\end{array}$} \\
\hline & & $\begin{array}{c}\text { Participação } \\
\text { igualitária; }\end{array}$ & & $\begin{array}{l}\text { Estrutura } \\
\text { igualitária; }\end{array}$ & $\begin{array}{l}\text { Estrutura } \\
\text { igualitária; }\end{array}$ & \multirow[t]{2}{*}{$\begin{array}{l}\text { Decisões são } \\
\text { coletivas. }\end{array}$} & \\
\hline & & $\begin{array}{c}\text { A ITES como } \\
\text { principal condutora } \\
\text { dos processos. }\end{array}$ & & $\begin{array}{l}\text { As decisões são } \\
\text { tomadas por meio } \\
\text { do consenso. }\end{array}$ & $\begin{array}{l}\text { As decisões são } \\
\text { tomadas por meio } \\
\text { do consenso. }\end{array}$ & & \\
\hline & \multirow[t]{2}{*}{$\begin{array}{l}\text { Importância da } \\
\text { Rede Baiana }\end{array}$} & \multirow[t]{2}{*}{$\begin{array}{l}\text { Fortalecimento das } \\
\text { finanças solidárias } \\
\text { como um todo. }\end{array}$} & $\begin{array}{c}\text { Troca de } \\
\text { informações. }\end{array}$ & \multirow[t]{2}{*}{$\begin{array}{c}\text { Estimulo ao } \\
\text { Companheirismo } \\
\text { e a solidariedade. }\end{array}$} & $\begin{array}{l}\text { Promoção de } \\
\text { intercâmbios; }\end{array}$ & $\begin{array}{l}\text { Crescimento pessoal } \\
\text { dos participantes; }\end{array}$ & \multirow[t]{2}{*}{$\begin{array}{l}\text { Fortalecimentos dos } \\
\text { BCDs através do } \\
\text { trabalho coletivo. }\end{array}$} \\
\hline & & & $\begin{array}{c}\text { Proporciona } \\
\text { interação entre os } \\
\text { bancos; }\end{array}$ & & $\begin{array}{c}\text { Troca de } \\
\text { informações. }\end{array}$ & $\begin{array}{l}\text { Fortalecimento das } \\
\text { instituições. }\end{array}$ & \\
\hline \multirow[t]{5}{*}{$\begin{array}{c}\text { Benefícios da Rede } \\
\text { Baiana }\end{array}$} & \multirow[t]{5}{*}{$\begin{array}{c}\text { Benefícios } \\
\text { alcançados pela } \\
\text { Rede Baiana }\end{array}$} & \multirow[t]{3}{*}{$\begin{array}{l}\text { Informações } \\
\text { políticas; }\end{array}$} & $\begin{array}{l}\text { Auxilia na } \\
\text { reabertura dos } \\
\text { bancos; }\end{array}$ & \multirow[t]{3}{*}{$\begin{array}{l}\text { Participação em } \\
\text { encontros e } \\
\text { intercâmbios; }\end{array}$} & $\begin{array}{l}\text { Promoção de } \\
\text { intercâmbios; }\end{array}$ & \multirow[t]{3}{*}{$\begin{array}{l}\text { Fortalecimento das } \\
\text { organizações; }\end{array}$} & \multirow[t]{2}{*}{$\begin{array}{l}\text { Melhoria da } \\
\text { comunicação; }\end{array}$} \\
\hline & & & Formação; & & Visitações; & & \\
\hline & & & $\begin{array}{l}\text { Capitação de } \\
\text { recursos; }\end{array}$ & & \multirow{2}{*}{$\begin{array}{c}\text { Troca de } \\
\text { experiência e } \\
\text { informações; }\end{array}$} & & Formações; \\
\hline & & \multirow[t]{2}{*}{$\begin{array}{l}\text { Conscientização da } \\
\text { necessidade de } \\
\text { articulação; }\end{array}$} & $\begin{array}{l}\text { Fortalece os BCDs } \\
\text { participantes; }\end{array}$ & \multirow{2}{*}{$\begin{array}{l}\text { Compartilhamento } \\
\text { de informações; }\end{array}$} & & \multirow[t]{2}{*}{ Aprendizagem; } & \\
\hline & & & $\begin{array}{l}\text { Desenvolvimento } \\
\text { pessoal; }\end{array}$ & & $\begin{array}{l}\text { Divulgação dos } \\
\text { BCDs; }\end{array}$ & & $\begin{array}{c}\text { Autonomia e } \\
\text { empoderamento dos }\end{array}$ \\
\hline \multicolumn{3}{|l|}{ Organizadores: } & alizadores: & & & & \\
\hline - FGV EAESP & & 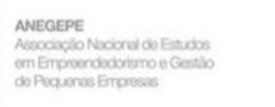 & & & & & \\
\hline
\end{tabular}




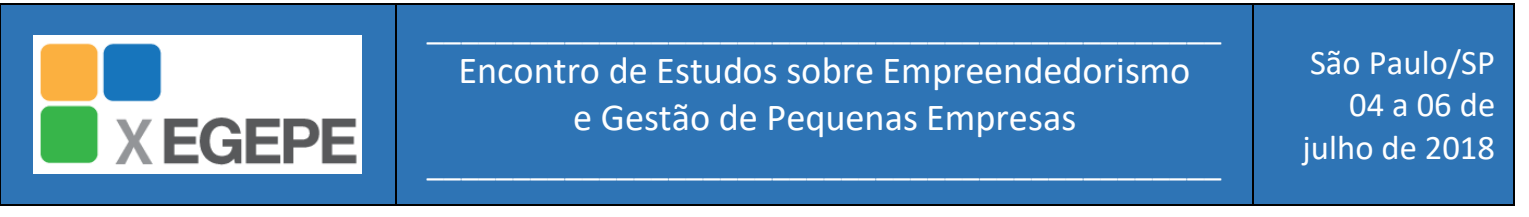

\begin{tabular}{|c|c|c|c|c|c|c|c|}
\hline & & \multirow{2}{*}{$\begin{array}{l}\text { Sentimento de } \\
\text { pertencimento a um } \\
\text { grupo; }\end{array}$} & Abre portas; & \multirow[t]{2}{*}{ Capacitações; } & & \multirow[t]{2}{*}{$\begin{array}{l}\text { Crescimento } \\
\text { profissional; }\end{array}$} & $\begin{array}{c}\text { trabalhadores do } \\
\text { BCD; }\end{array}$ \\
\hline & & & $\begin{array}{l}\text { Auxilia nas ações } \\
\text { do dia-a-dia do } \\
\text { banco; }\end{array}$ & & \multirow[t]{2}{*}{$\begin{array}{l}\text { Capacitação de } \\
\text { agentes; }\end{array}$} & & $\begin{array}{l}\text { Ampliação de } \\
\text { parcerias; }\end{array}$ \\
\hline & & \multirow{3}{*}{$\begin{array}{c}\text { Participação em } \\
\text { cursos, encontros, } \\
\text { intercâmbios e } \\
\text { visitas. }\end{array}$} & Integrar os bancos; & \multirow{2}{*}{$\begin{array}{l}\text { Resolução de } \\
\text { problemas; }\end{array}$} & & \multirow{3}{*}{$\begin{array}{c}\text { Ajuda no } \\
\text { desenvolvimento } \\
\text { das comunidades. }\end{array}$} & \\
\hline & & & $\begin{array}{c}\text { Melhoria na } \\
\text { Comunicação; }\end{array}$ & & Apoio técnico. & & $\begin{array}{c}\text { Recuperação de } \\
\text { BCDs fragilizados; }\end{array}$ \\
\hline & & & $\begin{array}{l}\text { Possibilita a troca } \\
\text { de informações. }\end{array}$ & $\begin{array}{l}\text { Captação de } \\
\text { recursos. }\end{array}$ & & & \\
\hline \multirow[t]{5}{*}{$\begin{array}{l}\text { Percepção sobre a } \\
\text { Rede Baiana }\end{array}$} & $\begin{array}{l}\text { Situação atual da } \\
\text { Rede Baiana }\end{array}$ & Fortalecida & Fragilizada & Fragilizada & $\begin{array}{c}\text { Fragilizada } \\
\text { (entrevistada 1); } \\
\text { Fortalecida, embora } \\
\text { com dificuldades } \\
\text { (entrevistada 2) } \\
\end{array}$ & Fortalecida & $\begin{array}{c}\text { Fortalecida, apesar } \\
\text { dos desafios } \\
\text { enfrentados. }\end{array}$ \\
\hline & \multirow[t]{4}{*}{$\begin{array}{c}\text { Desafios e } \\
\text { dificuldades }\end{array}$} & $\begin{array}{c}\text { Fragilidade das } \\
\text { entidades gestoras; }\end{array}$ & \multirow[t]{2}{*}{$\begin{array}{l}\text { Deslocamento dos } \\
\text { participantes; }\end{array}$} & \multirow[t]{2}{*}{$\begin{array}{c}\text { Deslocamento } \\
\text { dos participantes; }\end{array}$} & \multirow[t]{2}{*}{$\begin{array}{c}\text { Manter o } \\
\text { equilíbrio entre os } \\
\text { membros da rede; }\end{array}$} & $\begin{array}{l}\text { Cenário político e } \\
\text { econômico; }\end{array}$ & \multirow[t]{2}{*}{ Atual cenário político; } \\
\hline & & $\begin{array}{l}\text { Sustentabilidade e } \\
\text { fragilidade dos } \\
\text { BCDs; }\end{array}$ & & & & \multirow[t]{2}{*}{$\begin{array}{l}\text { Estrutura fragilizada } \\
\text { de alguns bancos; }\end{array}$} & \\
\hline & & $\begin{array}{c}\text { Deslocamento para } \\
\text { participar das ações } \\
\text { da Rede; }\end{array}$ & \multirow[t]{2}{*}{$\begin{array}{l}\text { Desinteresse em } \\
\text { envolve-se com as } \\
\text { atividades da rede. }\end{array}$} & \multirow[t]{2}{*}{$\begin{array}{l}\text { Desinteresse em } \\
\text { envolve-se com as } \\
\text { atividades da rede. }\end{array}$} & $\begin{array}{c}\text { Falta de } \\
\text { compromisso em } \\
\text { participar das } \\
\text { reuniões e eventos; }\end{array}$ & & \multirow[t]{2}{*}{$\begin{array}{l}\text { Pouco participação } \\
\text { dos BCDs nos eventos } \\
\text { da rede. }\end{array}$} \\
\hline & & $\begin{array}{l}\text { Sentimento de } \\
\text { pertencer a Rede. }\end{array}$ & & & $\begin{array}{l}\text { Falta de sentimento } \\
\text { de pertencimento da } \\
\text { rede; }\end{array}$ & $\begin{array}{c}\text { Trabalho } \\
\text { autogestionário. }\end{array}$ & \\
\hline
\end{tabular}

Fonte: elaborado pelos autores.

Organizadores:

-fgi eaesp

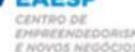




\section{Considerações finais e conclusão}

Este estudo teve como objetivo analisar como a Rede Baiana de BCDs contribui para o fortalecimento dos bancos comunitários da Bahia. Segundo Braz e Cardoso (2013) a ação em rede passa a ser indispensável para o sucesso de um empreendimento solidário, além de ser um processo de transformação da sociedade e de sua capacidade de mobilização. A cooperação, nesse sentido, se torna um meio para superação de crises que vem assombram a sociedade ao longo dos séculos e visualiza uma nova realidade que pode ser construída através da coletividade.

A Rede Baiana de Bancos Comunitários tem colaborado de forma significativa para superar os desafios enfrentados pelos bancos, permitindo que seus participantes possam se articular, compartilhar informações, trocar experiências, receber auxilio técnico e acessar recursos. Além disso, tem patrocinado a participação de seus componentes em reuniões, encontros, oficinas, intercâmbios, visitas técnicas e cursos de capacitação, contribuindo para profissionalização dos trabalhados que atuam diretamente na execução das atividades do banco, melhorando a sua gestão. Suas ações de modo geral têm fortalecido os bancos existentes dando maior visibilidade e ampliando sua oferta de serviços, além de atuar no apoio à expansão dessas experiências com a constituição de novos bancos, fortalecendo tanto o movimento de economia solidária, como também a própria rede.

A rede, na opinião da maioria de seus atores, vem se fortalecendo ao longo dos anos, mas também apresentam desafios que podem levar a seu enfraquecimento, como o atual cenário político-econômico que tem reduzido sua capacidade de articulação, além do processo de desmobilização por parte de seus integrantes.

As limitações apresentadas por este trabalho se referem a dois aspectos, um relacionado ao tempo de pesquisa, que inviabilizou a participação dos pesquisares nas reuniões realizadas pela rede, o que permitiria uma triangulação de informações entre o conteúdo das entrevistas e a observação dos atores em conjunto. A segunda limitação está relacionada a análise de um único caso pelos pesquisadores o que limita maiores conclusões. Como sugestão de próximas pesquisa indicamos ampliação deste estudo com realização de estudos comparativos com outras redes de bancos e com outras redes de economia solidária. No tocante às suas contribuições, este estudo permitiu identificar as contribuições da rede baiana de bancos comunitários para seus participantes, além de contribuir para um melhor entendimento do funcionamento de uma rede de economia solidária, especificamente uma rede formada por bancos comunitários de desenvolvimento.

\section{REFERÊNCIAS}

BRAZ, C. L. R.; CARDOSO, O. O. Economia solidária e redes sociais: antigos fenômenos, novas feições. Revista Organizações em Contexto, v. 9, n. 17, p. 59-77, 2013.

CASTELLS, Manuel. A Sociedade em Rede. São Paulo, Paz e Terra, 1999.

CASSANDRE, M. P.; SENGER, C. M.; AMARAL, W. R.; NETA, E. V. F. Políticas Públicas para a geração de trabalho e renda: economia solidária no paradoxo entre oportunidade e oportunismo. Gestão e Sociedade. Belo Horizonte. V. 7, № ${ }^{\circ}$ 17, p. 167-185. Maio/Agosto 2013. 
CORAGGIO, J. L. ¿ Qué es lo económico y que que es otra política? In: Sidney, L.; Henriques, F. C. A economia solidária na América Latina: realidades nacionais e políticas públicas. Rio de Janeiro: Pró Reitoria de Extensão UFRJ. 2012. p. 21-46.

DOWBOR, Ladislou. Democracia econômica: um passeio pelas teorias. Fortaleza: Banco do Nordeste, 2007.

EISENHARDT, K. M. Building Theories from Case Study Research. The Academy of Management Review Vol. 14, No. 4 (Oct., 1989), pp. 532-550

FRANÇA FILHO, G. C. Banco Palmas 15 Anos: resistindo e inovando. Núcleo de Economia Solidária - NESOL-USP e Instituto Palmas - São Paulo: A9 Editora, 2013. P. 42-59.

FRANÇA FILHO, G. C. Papel dos Bancos Comunitários de Desenvolvimento na visão da sua rede. Documento de trabalho. Versão inicial 2010. Disponível em: rbbcd@googlegroups.com. Acesso em: 26 de dezembro de 2016.

FRANÇA FILHO, G. C.; CUNHA, E. V. - Incubação de redes locais de economia solidária: lições e aprendizados a partir da experiência do projeto eco-luzia e da metodologia da ites/ufba. Revista O\&S. Salvador-BA, v.16 - n.51, p. 725-747 - Outubro/Dezembro - 2009.

FRANÇA FILHO, G. C.; LAVILLE, J.L. Economia solidária: uma abordagem internacional. Porto Alegre, Editora da UFRGS, 2004.

FRANÇA FILHO, G. C.; SANTANA, C. A. Bancos Comunitários de Desenvolvimento enquanto prática e dinâmica institucional. In: et al. Bancos comunitários de desenvolvimento (BCDs)como expressão de finanças solidárias: por uma outra abordagem da inclusão financeira. Fortaleza: Arte Visual, 2013. p. 50-96.

FREIRE, M. V. Banco Palmas 15 Anos: resistindo e inovando. Núcleo de Economia Solidária - NESOL-USP e Instituto Palmas - São Paulo: A9 Editora, 2013. P. 42-59.

GAIGER, Luiz Inácio Germany. A associação econômica dos pobres como via de combate às desigualdades. CADERNO CRH, Salvador, v. 22, n. 57, p. 563-580, Set./Dez. 2009.

GODFREY, P. C. Toward a Theory of the Informal Economy. The Academy of Management Annals, v. 5, n. 1, p. 231-277. 2011.

GODOY,A.S. Introdução à pesquisa qualitativa e suas possibilidades. ERA-Revista de Administração de Empresas. São Paulo, v. 35, n.2, p. 57-63, 1995.

GRANOVETTER, M. The strength of weak ties. American Journal of Sociology, v. 78, n. 6, p. 1360-1380, 1973.

GUARDA, M. G. Cooperação Nas Redes Organizacionais. In: Arlete redivo; Fiorelo Picoli; Salli Baggenstoss. (Org.). Administração Nas Perspectivas de Mercado, Organização, Trabalho e Desenvolvimento Regional. $1^{a}$ ed.Cáceres: UNEMAT, 2010, v. 1, p. 129-141.

HART, K. Informal Income Opportunities and Urban Employment in Ghana. The Journal of Modern African Studies. v. 11. n. 1, p. 61-89. 1973.
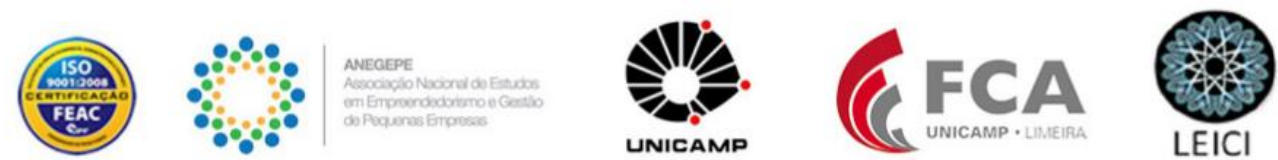
HIGA, Willian Toshio Minatogawa. AS REDES DE ECONOMIA SOLIDÁRIA: CONVERGÊNCIAS E DIVERGÊNCIAS ENTRE A CIDADANIA E A INOVAÇÃO TECNOLÓGICA. In: I Simpósio Estadual Lutas Sociais na América Latina, 2005, Londrina/PR. Gepal - Ciências Humanas UEL, 2005.

IPEA - INSTITUTO DE PESQUISA ECONÔMICA APLICADA. O Sistema de Indicadores de Percepção Social (Sips). 2011. Disponível em: http://www.ipea.gov.br/portal/images/stories/PDFs/SIPS/110112_sips_bancos.pdf.

Acesso em: 19 dezembro. 2015

LAVILLE, C.; DIONNE, J. A construção do saber: manual de metodologia da pesquisa em ciências humanas / tradução Heloisa Monteiro e Francisco Settineri. - Porto Alegre: ARTMED, 1999

LAVILLE, J.; GAIGER.L. Economia Solidária. In: HESPANHA, Pedro [et ali.]. Dicionário Internacional da outra economia. Coimbra: Almedina, 2009, p. 162-168.

MACIEIRINHA, L. M. Dinamização da Cooperação Inter-Empresarial: Proposta de aumento de eficiência pela identificação e fecho de gaps Teoria - Concepção Implementação. O CASO SISCOOP. Dissertação de Mestrado em Ciências Econômicas- Universidade do Porto- 2009.

MANCE, E. A. Redes de Colaboração Solidária. Petrópolis. Editora Vozes, 2002.

MANCE, E. A. Redes de Economia Solidária. In: Fundação Luís Eduardo Magalhães. Economia Solidária: desafios para um novo tempo. Salvador - FLEM, 2003. P. 71 82.

MELO NETO, J. J; MAGALHÃES, S. Bancos Comunitários de Desenvolvimento: uma rede sobre o controle da comunidade. Fortaleza: Arte Visual, 2007.

PROJETO ECOSMAR. Relatório Final: etapa I. Vera Cruz-Ba, maio, 2008 b.

RIGO, A. S. Moedas sociais e bancos comunitários no brasil: aplicações e implicações, teóricas e práticas. Tese (Doutorado em Administração) - Universidade Federal da Bahia, Salvador, 2014.

RIGO, A. S.; CANÇADO, A. C. Gestão social e construção de espaços públicos: reflexões a partir da Rede Brasileira de Bancos Comunitários do Brasil. Administração Pública e Gestão Social, v. 7, n. 1, p. 38-44, 2015.

RIGO, A. S., FRANÇA FILHO, G. C.; LEAL, L. P. Os bancos comunitários de desenvolvimento na política pública de finanças solidárias: apresentando a realidade do Nordeste e discutindo proposições. Desenvolvimento em Questão. v. 13, n. 31, p.70-107, 2015.

SINGER, P. Banco Palmas 15 Anos: resistindo e inovando. Núcleo de Economia Solidária - NESOL-USP e Instituto Palmas - São Paulo: A9 Editora, 2013. P. 27-31.

VERSCHOORE, Jorge R. Redes de Cooperação Interorganizacionais: a identificação de atributos e benefícios para um modelo de gestão. Universidade Federal do Rio Grande do Sul. Tese de Doutorado, 2006.

YIN, R. K. Estudo de caso: planejamento e métodos. 5. ed. Porto Alegre: Bookman, 2015. 320 p.
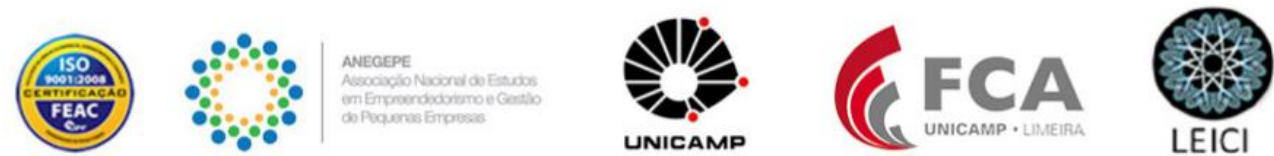